\title{
Determination of Trans-10-Hydroxy-2-Decenoic Acid in Royal Jelly by High Performance Liquid Chromatography after Different Bee Feeding
}

\author{
Ralitsa Balkanska* \\ Department of Special Branches - Bees, Institute of Animal Science, 2230 \\ Kostinbrod, Bulgaria \\ *Corresponding author
}

\section{A B S T R A C T}

\begin{tabular}{|l|}
\hline K e y w o r d s \\
$\begin{array}{l}\text { Royal jelly, trans-10- } \\
\text { hydroxy-2-decenoic acid } \\
\text { (10-HDA), Bee feeding }\end{array}$ \\
\hline Article Info \\
\hline $\begin{array}{l}\text { Accepted: } \\
\text { 30 March } 2018 \\
\text { Available Online: } \\
\text { 10 April 2018 }\end{array}$ \\
\hline
\end{tabular}

Keywords

Royal jelly, trans-10 (10-HDA), Bee feeding

\section{Introduction}

Royal jelly (RJ) is a secretion from the hypopharyngeal and mandibular glands of worker honey bees (Apis mellifera L.). It is used to feed the bee larvae up to three days and queen bee for both her larval and adult life (Wytrychowski et al., 2014). RJ is generally regarded as the major reason of castle determination in the bee family ( $\mathrm{Hu}$ et al., 2017). It is well know that the composition of RJ is quite complex. It contains mainly proteins, sugars, amino acids, vitamins, mineral elements and fatty acids (Muresan et al., 2016). The unique and the most interesting feature of RJ are its fatty acids. The major fatty acid in RJ is trans-10-hydroxy-2- decenoic acid (10-HDA). No other natural product containing 10-HDA has been reported (Genc and Aslan, 1999). Based on RJ composition it is extensively used as a cosmetic or dietary supplement. It claims various health benefits (Jamnik et al., 2007; Bogdanov, 2017). A lot of researchers believe that they are attributed mainly to 10-HDA presented in RJ. Several pharmacological effects of 10-HDA have already been demonstrated (Bogdanov, 2017), including antibacterial and immuno activating (Melliou and Chinou, 2005), collagen promoting and skin protecting (Koya-Miyata et al., 2004), immuno-modulating and anti-cancer (Gasic et al., 2007; Vucevic et al., 2007; Sugiyama et al., 2013), anti-rheumatic (Yang et al., 2010), 
anti-ulcer (Fang et al., 1994). In the last years, RJ consumption as dietary supplement or in cosmetics is constantly increasing all over the world. In 2016, an international standard for RJ was submitted by the International Organization for Standardization. National standards have been established in some countries such as Switzerland, Japan and Brazil (Sabatini et al., 2009).

$\mathrm{RJ}$ is a bee product with great potential as a supplementary food and in the future it will be very important for the pharmaceutical industry. This means that identification of main quality parameters and standardization procedures for RJ quality are needed. Thus, the aim of this study is first to determine the content of 10-HDA in Bulgarian RJ and second to identify if the content of 10-HDA in RJ depends on supplementary feeding of the honey bees.

\section{Materials and Methods}

A total of $50 \mathrm{RJ}$ samples were analyzed. The samples were harvested from experimental apiary of the Institute of Animal Science Kostinbrod during the period May - August 2013 and were stored at $-20^{\circ} \mathrm{C}$ until the analysis.

In the experiment for RJ production a total of 9 bee families were observed -6 experimental (3 bee families fed with sugar : water 1:1 and $5 \mathrm{ml} / \mathrm{l}$ vitamin $\mathrm{AD}_{3} \mathrm{E}$ (Kombisol $\mathrm{AD}_{3} \mathrm{E}$, Trouw Nutrition International) as a supplement; 3 bee families fed with $10 \%$ baker's yeast in sugar: water 1:1) and 3 control (fed only with sugar syrup).

The following RJ samples were obtained: 14 RJ samples from bee families fed with vitamin $\mathrm{AD}_{3} \mathrm{E} ; 14 \mathrm{RJ}$ samples from the families fed with $10 \%$ baker's yeast in sugar syrup; $22 \mathrm{RJ}$ samples from the control group. The RJ is obtained by the artificial wax cups method
(Grout, 1992) on the third day after bee larvae grafting. The sugar syrup is administered in a dose of $300 \mathrm{ml}, 2$ times per week in the bee feeders of the experimental and control groups bee families.

\section{Instrument}

HPLC analysis was performed using an Aligent HPLC 1100 Series, equipped with Diode Array Detectors (DAD) G1315B and column Intersil 5 ODS-2 $(250 \mathrm{~mm}$ x $4.6 \mathrm{~mm} \mathrm{~L}$ $\mathrm{x}$ I.D., particle size $5 \mu \mathrm{m})$. The maximum absorbance of 10-HDA was confirmed to be $215 \mathrm{~nm}$. The mobile phase was mixture of methanol and distillated water $(35: 65 \mathrm{v} / \mathrm{v})$ and acetic acid $(\mathrm{pH} 3)$. The flow rate was 1.0 $\mathrm{ml} / \mathrm{min}$. The total run time for each sample was 10 min. A standard trans-10-hydroxy-2decenoic acid (10-HDA) was purchased from Larodan AB, Sweden (Lot no: E013:1). Stock standard solutions were prepared in methanol. Each measurement was conducted in triplicate. All chemicals were of HPLC grade and used without further purification.

\section{Sample preparation}

The sample preparation was with solid-phase extraction (SPE) using $\mathrm{C}_{18} \mathrm{XF}$ extraction disks. The HPLC analysis was done at Institute of Organic Chemistry with Centre of Phytochemistry, Sofia, Bulgaria.

\section{Statistical analysis}

The data analysis involved estimation of means and standard deviations (SD) using SPSS version 21 for Windows. Student $t$-test was used to determine which means were statistically significant $(\mathrm{p}<0.05)$.

\section{Results and Discussion}

Our investigation initially aimed to determine the content of 10-HDA in RJ samples from 
Bulgaria for the first time. The results showed presence up to $1.5 \% 10$-HDA in all analyzed samples. For all samples $(\mathrm{n}=50)$ the ranges are $(1.64-2.73 \%)$. The mean value and standard deviation is $1.97 \pm 0.22 \%$. It is well know that the main quality factors of RJ have been described and the lipid fraction as a marker and hence a criterion by which to determine the authenticity of the product. Presently, 10HDA can be used for routine testing of RJ authenticity. However, the concentration of this acid varies in wide limits. According to Sabatini et al., (2009) the presence of 10-HDA should be more than $1.4 \%$.

These findings for 10-HDA from the control group bee families can be used as a first study for determination of 10-HDA in RJ samples from Bulgaria (Table 1). For these samples the minimal and maximal values are 1.64 $2.32 \%$. A lot of authors present minimal concentration of 10-HDA in RJ samples. Bloodworth et al., (1995) reported that only in four countries - Australia, Korea, Japan and Thailand - the presence of 10-HDA is used as an improvement for pure RJ. According to Thai specifications, the amount of 10-HDA should not be less than $1.5 \%$ for RJ. Also, in Turkey the minimum amount of 10-HDA in pure RJ must be $1.4 \%$. Similar to our results are presented by Mureşan et al., (2016). They reported that Romanin RJ had 10-HDA content from $1.35 \%$ to $2.03 \%$. Greek RJ had higher maximal value for 10-HDA content from $0.8 \%$ to $6.5 \%$ (Kanelis et al., 2015). The content of 10-HDA in Croatian RJ varied from $1.56 \%$ up to $3.78 \%$ (Flanjak et al., 2017).

According to Garcia-Amoedo and AlmediaMuradian (2003) the 10-HDA content in pure Brazilian RJ ranged between $1.58-3.39 \%$. According to the ISO royal jelly international standard (ISO 12824:2106, 2016), the minimum concentration of $10-\mathrm{HDA}$ is $1.4 \%$ for pure RJ.
As can be seen from Table 1 RJ samples of bee families fed with baker's yeast have significantly higher 10-HDA value compare to the samples from the control group bee families $(p<0.01)$. The results for RJ samples from bee families fed with vitamin $\mathrm{AD}_{3} \mathrm{E}$ compare to the samples from the control group are not significant. RJ is made in the hypopharyngeal glands of young worker bees. Apparently, the presence of 10-HDA is connected with the functioning of these glands of the young worker bees. It can be expected that different supplements in the bee feeding can change the lipid fraction of RJ. The present results show for the first time that supplementary feeding with baker's yeast can increase the content of 10-HDA in RJ samples. We can suppose that these results are connected with better development of the bee glands after supplementary feeding. It is worth noting that vitamins $\mathrm{AD}_{3} \mathrm{E}$ do not affect this secretion. The lipid fraction is present in variable concentrations (Sabatini et al., 2009) but no doubt represents the most important of RJ components. Hydroxy acids with 10 carbon atoms such as 10-hydroxydecenoic and 10hydroxy-2-decenoic acid can be found in high concentrations in RJ. Moreover, their concentration in RJ can be effect after feeding of the bees (Fig. 1).

The results for 10-HDA ranges are presented on Figure 2. The results show narrower ranges of variation in the medians in the RJ samples from the experimental groups compared to the RJ samples from the control group.

Figure 3 shows a standard of 10-HDA obtained after absorbance at $215 \mathrm{~nm}$ and retention time was found to be $12.491 \mathrm{~min}$.

A direct relationship was estimated between the peak areas and the amount of 10-HDA standard. The correlation equation of this relationship was calculated as $\mathrm{y}=128164 \mathrm{x}+731.64\left(\mathrm{R}^{2}=0.9997\right)$. 
Fig.1 Box plot diagram of 10-HDA. The minimum, maximum and median values are shown

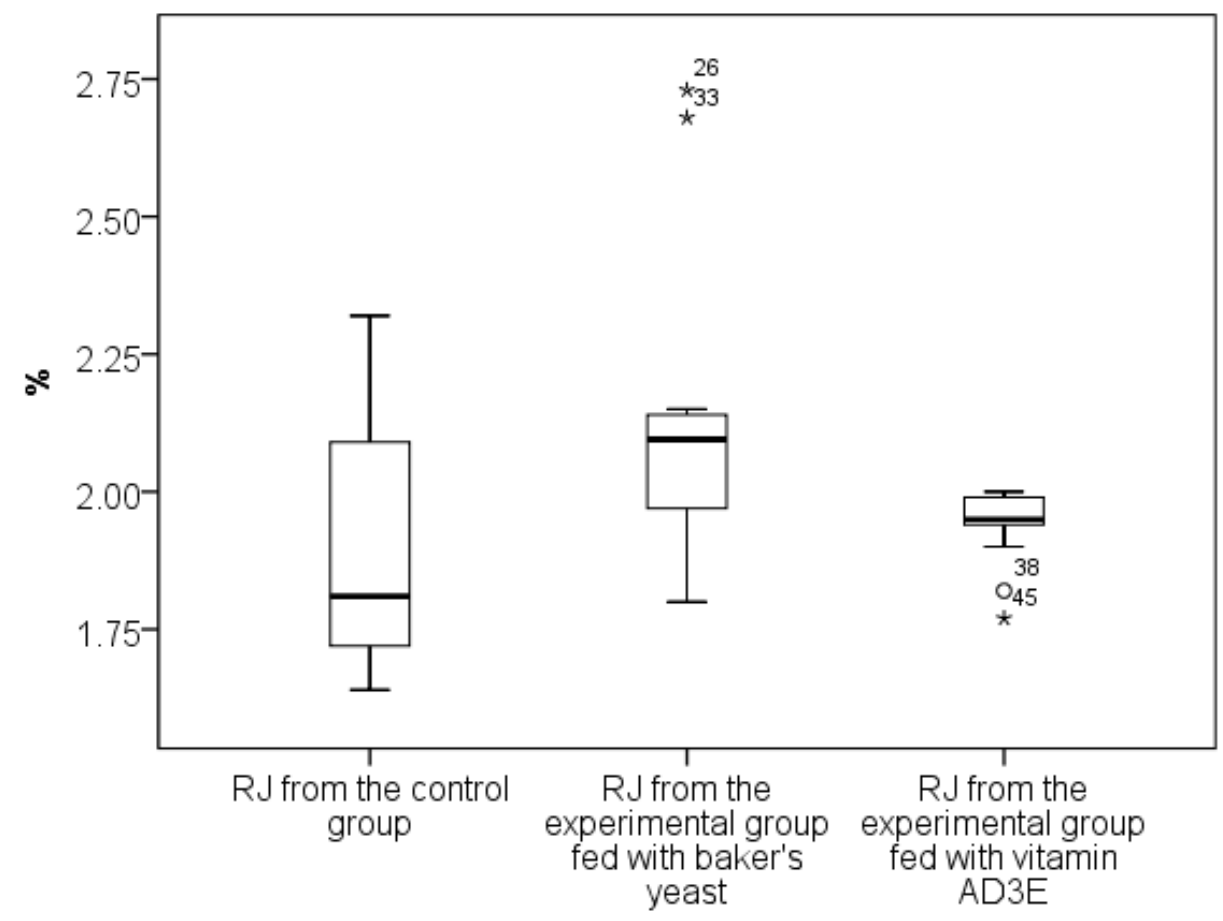

Fig.2 Chromatogram of 10-HDA standard

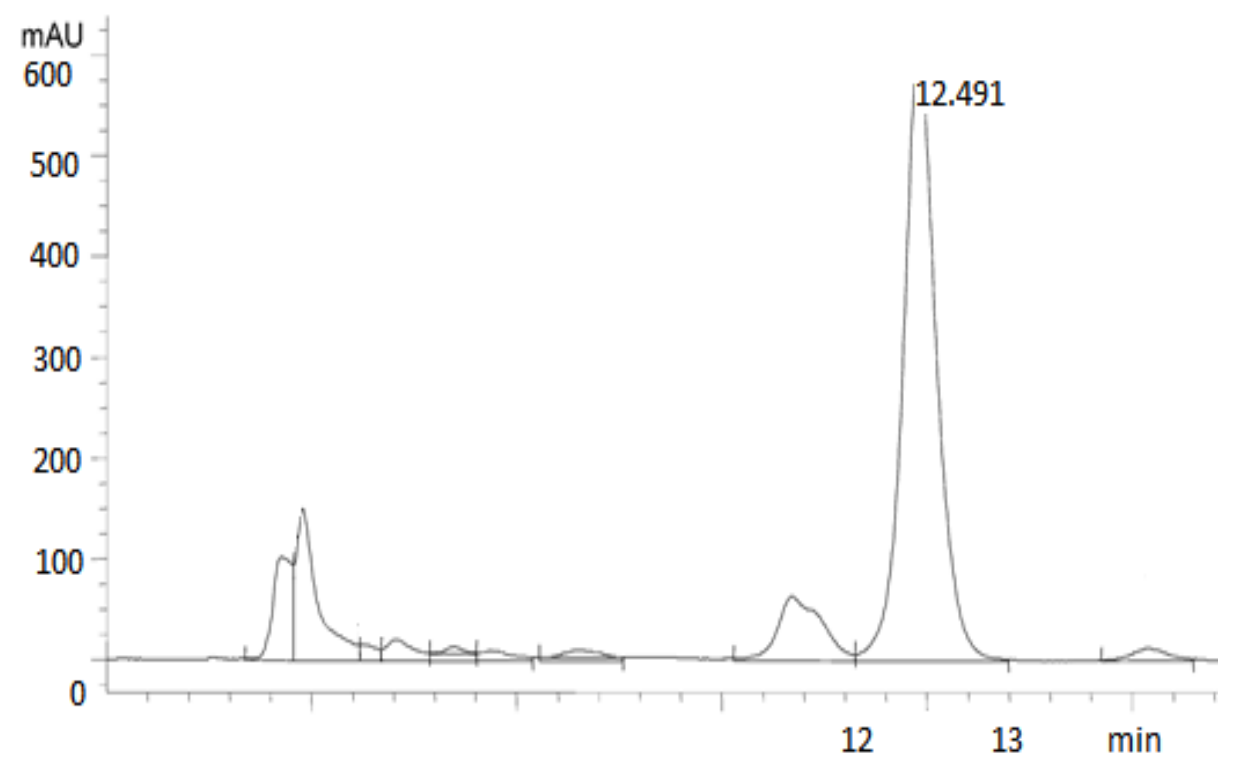


Fig.3 Standard curve for 10-HDA standard, $\mathrm{mg} / \mathrm{ml}$

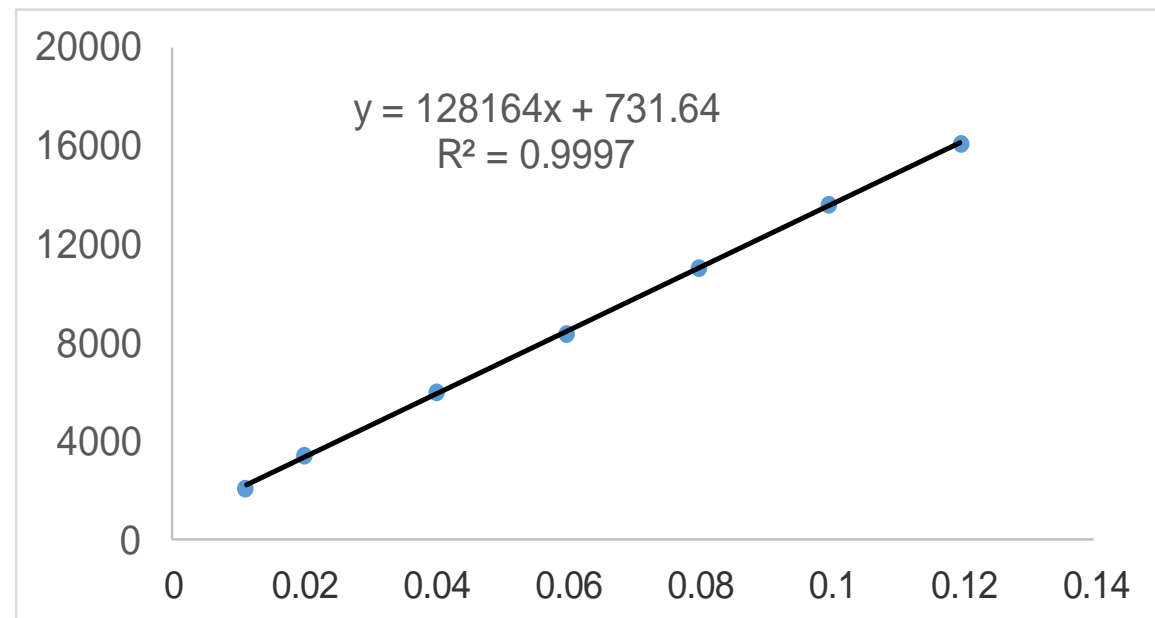

Table.1 Determination of trans-10-hydroxy-2-decenoic acid (10-HDA) in RJ samples from the control group bee families and bees fed with baker's yeast and vitamin $\mathrm{AD}_{3} \mathrm{E}$

\begin{tabular}{|c|c|}
\hline Type of feeding & Mean \pm SD \\
\hline RJ samples from the control group bee families, $(n=22)$ & $1.89 \pm 0.22$ \\
\hline RJ samples from bee families fed with baker's yeast, $(n=14)$ & $2.13 * \pm 0.27$ \\
\hline RJ samples from bee families fed with vitamin $\mathrm{AD}_{3} \mathrm{E},(\mathrm{n}=14)$ & $1.94 \pm 0.07$ \\
\hline
\end{tabular}

Note: Statistically significant differences $(\mathrm{p}<0.01)$ between RJ samples from the control group and the bee families fed with baker's yeast.

Range (1.64 - 2.32\%) for 10-HDA in RJ samples received from the control group bee families could be used as a first proposal for Bulgarian standard for 10-HDA.

Our findings are in argument with ISO royal jelly international standard and they provide a comprehensive and detailed evaluation of the content of 10-HDA. Also this is the first data for significantly higher content of 10-HDA in RJ samples after feeding of the bee families with baker's yeast $(p<0.01)$ compare to the control group bee families. The data shows that some components in RJ composition such as $10-$ HDA is influenced by supplementary feeding of the bee families.

\section{Acknowledgment}

This research was financed by Project BG051PO001-3.3.06-0033 "Support for the development of doctoral graduate students and young researchers" OP "Human resources development" Ministry of Labour and social policy, European Social Fund (ESF).

\section{References}

Bloodworth, B. C., C. S. Harn, C. T. Hack and Boon, Y. O. 1995. Liquid chromatographic determination of trans-10-hydroxy-2decenoic acid content of commercial products containing royal jelly. J. Assoc. Off. Anal. Chem. Int. 78, $1019-1023$.

Bogdanov, S. Royal Jelly, Bee Brood: Composition Nutrition Health. The Royal Jelly Book, Chapter 2, 2017, p 6.

Fang, E., H. Zhou, H. Xu and Xing, M. 1994. Antiulcer effects of 10-hydroxy-2-decenoic acid in rats. Zhongguo aolixue Tongbao, 10(2), $9-42$.

Flanjak, I., M. Jakovljević, D. Kenjerić, M. Stokanović, L. Primorac and Rajs, B. 2017. Determination of (2E)-10-hydroxydec-2- 
enoic acid in Croatian royal jelly by highperformance liquid chromatography. Croat. J. Food Sci. Technol., 9 (2) 152 - 157.

Garcia-Amoedo, L. H. and Almeida-Muradian, L. B. 2003. Determination of trans 10hydroxy-2-decenoic acid (10-HDA) in Brazilian royal jelly. Cienc. Tecnol. Aliment, 23, $62-65$.

Gasic, S., D. Vucevic, S. Vasilijic, M. Antunovic, I. Chinou and Colic, M. 2007. Evaluation of the immunomodulatory activities of royal jelly components in vitro. Immunopharmacol and Immunotoxicol., 29(3-4), $521-536$.

Genc, M. and Aslan, A. 1999. Determination of trans-10-hydroxy-2-decenoic acid content in pure royal jelly and royal jelly products by column liquid chromatography. J. Chromatogr. A., 839, $265-268$.

Grout, R. A. The hive and the honey bee. Revised edition, Dadant \& Sons, USA; 1992 p. 23.

Hu F. L., K. Bíliková, H. Casabianca, G. Daniele, F. S. Espindola, M. Feng, C. Guan, B. Han, T. Kraková, J. Li, L. Li, X. Li, J. Šimúth, L. $\mathrm{Wu}, \mathrm{Y}$. Wu, X. Xue, Y. Xue, K. Yamaguchi, Z. Zeng, H. Zheng and Zhou, J. 2017. Standard methods for Apis mellifera royal jelly research. Journal of Apicultural Research, $1-69$.

ISO 12824:2106. (2016). Royal jellySpecifications.

Jamnik, P., D. Goranovic and Raspor, P. 2007. Antioxidative action of royal jelly in the yeast cell. Exp. Gerontol., 42, $594-600$.

Kanelis, D., C. Tananaki, V. Liolios, M. Dimou, G. Goras, M. A. Rodopoulou, E. Karazafiris and Thrasyvoulou, A. 2015. A suggestion for royal jelly specifications. Arch. Hig. Rada Toksikol. 66, 275 - 284.

Koya-Miyata, S., I. Okamoto, S. Ushio, K. Iwaki, M. Ikeda and Kurimoto, M. 2004.
Identification of a collagen productionpromoting factor from an extract of royal jelly and its possible mechanism. Biosci. Biotechnol and Biochem, 68(4), 767 - 773.

Melliou, E. and Chinou, I. 2005. Chemistry and bioactivity of royal jelly from Greece. J. Agric. Food Chem., 53, 8987 - 8992.

Mureşan, I. C., L. Al. Mãrghitaş, Dezmirean, S.D., Bobiş, O., Bonta, V., Zacharias, I., Mărgăoan, R. and Paşca, C. 2016. Quality Parameters for commercialized Royal Jelly, Bulletin UASVM Anim. Sci. Biotechn. 73 (1), $1-8$.

Sabatini, A. G., G. Marcazzan, M. F. Caboni, S. Bogdanov and Almeida-Muradian, L. B.2009. Quality and standardisation of royal jelly. JAAS. 1, $1-6$.

Sugiyama, T., K. Takahashi, A. Kuzumaki, S. Tokoro, P. Neri and Mori, H. 2013. Inhibitory mechanism of 10-hydroxy-trans2-decenoic acid (royal jelly acid) against lipopolysaccharide- and interferon-betainduced nitric oxide production. Inflammation, 36(2), $372-378$.

Vucevic, D., E. Melliou, S. Vasilijic, S. Gasic, P. Ivanovski, I. Chinou and Colic, M. 2007. Fatty acids isolated from royal jelly modulate dendritic cell-mediated immune response in vitro. Int. immunopharmacol, 7(9), $1211-1220$.

Wytrychowski, M., J. O, Paisse, H. Casabianca and Daniele, G. 2014. Assessment of royal jelly freshness by HILIC LC-MS determination of furosine. Ind. Crops Prod., $62313-317$.

Yang, X. Y., D. S. Yang, Z. Wei, J. M. Wang, C. Y. Li, H. Ye, K. F. Lei, X. F. Chen, N. H. Shen, L. Q. Jin and Wang, J. G. 2010. 10Hydroxy-2-decenoic acid from royal jelly: A potential medicine for RA. J. Ethnopharmacol., 128(2), 314-321.

\section{How to cite this article:}

Ralitsa Balkanska. 2018. Determination of Trans-10-Hydroxy-2-Decenoic Acid in Royal Jelly by High Performance Liquid Chromatography after Different Bee Feeding. Int.J.Curr.Microbiol.App.Sci. 7(04): 3738-3743. doi: https://doi.org/10.20546/ijcmas.2018.704.420 